\title{
LA REPRESENTACIÓN DEL CUERPO DÓCIL EN EL INFIERNO VERDE DE JOSÉ MARÍN CAÑAS
}

\author{
Irene González Muñoz
}

\begin{abstract}
RESUMEN
En el marco de la jornada de investigación "Representaciones Literarias del Cuerpo", el objetivo de este artículo sobre la novela El Infierno Verde, de José Marín Cañas, consiste en demostrar cómo se representa el cuerpo humano en el contexto de la guerra. Para esto, se parte de las propuestas de Michel Foucault en Vigilar y Castigar y en Historia de la Sexualidad, textos en los que este autor plantea el cuerpo como el elemento central a partir del cual se funda simbólica y prácticamente un orden social.

Palabras clave: Literatura costarricense, novela, cuerpo, Marín Cañas-José.
\end{abstract}

\section{ABSTRACT}

In the framework of research journey "Literary Representations of the Body", the objective of this article on the novel El infierno verde, of José Marín Cañas, is to demonstrate how the human body is represented in the context of war. For this, some of the proposals of Michel Foucault in Discipline and Punish and History of Sexuality, texts in which the author presents the body as the central element from which it is founded and practically symbolic social order are used.

Key words: Costa Rican Literature, novel, body, Marín Cañas-José.

[...] y quedaron tronchados, como bejucos sobre troncos de quebracho.

[...] Los mató el polvo arcilloso en las gargantas tumefactas.

[...] A eso fui yo y en eso estoy.

(Marín Cañas 2005: XV)

ML. Irene González Muñoz. Profesora de la Escuela de Filología, Lingüística y Literatura de la Universidad de Costa Rica.

Correo electrónico: irenego123@gmail.com

Recepción: 14- 03- 2013

Aceptación: 20- 04- 2013 
La intención de realizar una lectura del texto El Infierno Verde, de José Marín Cañas, a partir de los postulados de Michel Foucault en relación con el dominio del cuerpo en la modernidad, reside en demostrar cómo se construye, a través del lenguaje literario y en un texto de ficción cuyo mundo mostrado remite al contexto de la guerra, la representación del cuerpo dócil, básicamente en la figura del protagonista de la novela, el soldado anónimo.

\section{Consideraciones teóricas}

Tal como lo plantean diversos críticos de la Modernidad, esta puede entenderse, entre otras posibilidades, como un período que se caracteriza por la conformación del ser humano como un sujeto colectivo altamente determinado por las circunstancias histórico-sociales, concretamente, las de las relaciones de producción. Entre estos críticos podemos citar, ante todo, a Karl Marx en las Tesis sobre Feuerbach y, nuevamente, a Marx y a Engels en el Manifiesto del Partido Comunista.

Precisamente, en el primero de estos documentos Marx afirma que "la esencia humana no es algo abstracto e inmanente a cada individuo. Es, en realidad, el conjunto de las relaciones sociales" que la conforman (Marx 1987: 667); es decir, para este crítico de la Modernidad el ser humano se construye en su relación con la sociedad en la que se encuentra inmerso y, siguiendo su propuesta, esta construcción depende de las condiciones materiales de trabajo/ producción en su devenir histórico, lo que supone un dominio no solo de la moral social del sujeto, sino también el dominio de su cuerpo.

Precisamente sobre este último aspecto, Marx plantea que el modo de producción capitalista reorganizó las relaciones del sujeto con su cuerpo, esto se da desde el momento en que el sujeto 'alquila' su fuerza de trabajo a un sistema que se nutre de ella en la generación de ganancias económicas, pues a partir de esta transacción se crean una serie de reglas para el cuerpo y para el espacio en el que este se va a desenvolver: la fábrica. Se trata, entonces, de reglas que están orientadas a maximizar la rapidez y a aprovechar la capacidad productiva del cuerpo humano. Ahora bien, conjuntamente con estas reglas prácticas, se genera además una serie de discursos para persuadir, moralmente, al ser humano de la importancia de su trabajo para acceder a una sociedad productiva. Son discursos en los que se establecen formas de pensar, de sentir y de actuar del sujeto para su inserción dentro una fuerza productiva y dentro de una determinada clase social.

De acuerdo con Marx, estos discursos se extienden y atraviesan la cultura cotidiana; por ejemplo, en la práctica administrativa de las empresas y en el sistema educativo ${ }^{1}$ con la finalidad de formar y de disciplinar al sujeto dentro del contexto productivo. Por esto, concluye que el trabajo además de producir mercancías, produce también al sujeto/obrero como mercancía del sistema capitalista. Siguiendo la propuesta anterior, se puede afirmar, entonces, que el cuerpo funciona como un texto en el que se inscriben las relaciones sociales de producción y de dominación.

En consonancia con la idea anteriormente expuesta, Michel Foucault, en Vigilar y Castigar. Nacimiento de la Prisión (publicado por primera vez en 1975), parte de la idea de que el cuerpo humano es el elemento central a partir del cual se funda simbólica y prácticamente un orden social. Según Foucault, la utilización económica del cuerpo está relacionada con lo que él denomina el cerco político del cuerpo, al que se refiere como un campo político en el que "las relaciones de poder operan sobre él [el cuerpo] una presa inmediata; lo cercan, lo marcan, 
lo doman, lo someten a suplicio, lo fuerzan a unos trabajos, lo obligan a unas ceremonias, exigen de él unos signos (Foucault 2005: 32)”. De acuerdo con este filósofo, y como ya se ha dicho, este cerco político está relacionado con la utilización económica del cuerpo, pues su conformación como fuerza de trabajo solo es posible si está unido a un sistema de sujeción; es decir, si es un cuerpo sometido.

Para el sometimiento del cuerpo se requiere de un saber sobre este (aunque no necesariamente sobre la ciencia de su funcionamiento) y de un dominio de sus fuerzas, para constituir una serie de representaciones o 'invenciones' sobre él, conjunto de representaciones que Foucault designa como la tecnología política del cuerpo, la cual concibe, además, como una instrumentación multiforme (a pesar de sus resultados tan efectivos) que no es posible localizar en una institución ni en algún aparato estatal en especial, ya que debe asumirse como una estrategia o una serie de estrategias que no se aplican como una prohibición o un mandato desde el poder a quienes no lo tienen, sino que se trata de una microfísica del poder que invade, atraviesa y se apoya en aquellos que son sometidos, esto es lo que él llama la omnipresencia del poder.

\begin{abstract}
Omnipresencia del poder: no porque tenga el privilegio de reagruparlo todo bajo su invencible unidad, sino porque se está produciendo a cada instante, en todos los puntos, o más bien en toda relación de un punto a otro. El poder está en todas partes; no es que lo englobe todo. Y "él” poder, en lo que tiene de permanente, de repetitivo, de inerte, de autorreproductor, no es más que el efecto de conjunto que se dibuja a partir de todas esas movilidades, el encadenamiento que se apoya en cada una de ellas y trata a su vez de fijarlas. Hay que ser nominalista, sin duda: el poder no es una institución, y no es una estructura, no es cierta potencia de la que algunos estarían dotados: es el nombre que se presta a una situación estratégica compleja en una sociedad dada. (Foucault 2002: 89)
\end{abstract}

En otras palabras, se trata de relaciones complejas del poder-saber que permean la sociedad y que no se localizan, ingenuamente, en la interacción del Estado con los ciudadanos, sino que deben entenderse como el "conjunto de los elementos materiales y de las técnicas que sirven de armas, de relevos, de vías de comunicación y de puntos de apoyo a las relaciones de poder y de saber que cercan los cuerpos humanos y los dominan haciendo de ellos unos objetos de saber" (Foucault 2005: 35).

Siguiendo estos planteamientos de Foucault, el cuerpo humano, como fuerza de producción, no existe como un elemento meramente biológico o material, sino que es el producto de un sistema político y de los mecanismos del poder, los cuales le indican cómo comportarse y qué postura adoptar en función de la labor que ejecute dentro de ese sistema. Se asume así el hombre-máquina, el cual se construye a partir de dos registros:

1. El anatomo-metafísico: propuesto, en primera instancia, por Descartes ${ }^{2}$ y continuado por el discurso de los médicos y de los filósofos.

2. El técnico-político: conformado por un conjunto de reglamentos militares, escolares, hospitalarios y por una serie de procedimientos para controlar y corregir las operaciones del cuerpo.

El primer registro supone conocer el funcionamiento y la explicación del cuerpo humano, se trata del cuerpo inteligible; el segundo supone conocer su sumisión y su utilización, es el cuerpo útil. Del cruce de ambos registros; es decir, del cuerpo analizable (reducción materialista del alma) y del cuerpo manipulable (el cual implica una teoría general de la educación), surge el cuerpo dócil, el cual se define, según Foucault, como "un cuerpo que puede ser sometido, que puede ser utilizado, que puede ser transformado y perfeccionado "(Foucault 2005: 140). 
La disciplina es el mecanismo empleado para someter, transformar y perfeccionar el cuerpo dócil, pues a través de ella se garantiza no solo el control de sus operaciones, sino también la sujeción constante de sus fuerzas al sistema, ya sea este político o económico, lo cual refuerza la relación de docilidad-utilidad del cuerpo humano en el espacio social (Foucault 2005). En otras palabras, el cuerpo dócil es el resultado de una anatomía política, la cual debe ser entendida como las marcas que la aplicación de las técnicas disciplinarias producen en los cuerpos a los que encauzan y gobiernan, sobre todo a través de procedimientos de análisis y de diferenciación.

Entre estas técnicas disciplinarias empleadas para la conformación del cuerpo dócil, Michel Foucault propone y explica algunas que vincula ya sea con el sistema escolar, con la institución militar, con el espacio hospitalario o con la fábrica. Entre ellas se refiere a la clausura, la organización del espacio, el empleo del tiempo y el aprendizaje por segmentos sucesivos, entre otras.

\section{Sobre la novela y su crítica}

Antes de establecer algunos aspectos importantes sobre la producción y la recepción de El Infierno Verde dentro del ámbito de la crítica y de la historiografía literaria en nuestro país, cabe referirnos al argumento del texto en cuestión.

En la novela, el protagonista, un soldado anónimo paraguayo (pues nunca se conoce su nombre), que se enlista para defender la soberanía de su país en el conflicto bélico por la región del Chaco Boreal entre Bolivia y Paraguay, nos relata las experiencias vividas en esta guerra. Al principio de la historia, a este personaje lo embarga un sentimiento nacionalista, pero una vez en el campo de batalla, junto con sus compañeros: Nitsuga, Ezcarru, Curriche y Rodríguez, descubre que la guerra no tiene sentido. No obstante, todas las atrocidades de las que es testigo y a pesar de haber sido gravemente herido en una pierna, regresa al campo de batalla después de una larga recuperación. Finalmente, cuando la mayoría de sus compañeros han muerto, agotado de todo, decide desertar junto con Rodríguez. Durante el viaje de escape se pierden en la selva. Primero muere Rodríguez y luego el protagonista.

La novela fue publicada en forma de libro en 1935 por la Editorial Espasa-Calpe, en España, pero antes había sido publicada en Costa Rica como un "diario por entregas" en el periódico La Hora, en el cual su autor fungía como director. La idea de publicarla como un diario obedece a la intención de Marín Cañas de que se recibiera como un documento testimonial narrado por el protagonista de la historia, un soldado paraguayo, anónimo como ya se ha dicho, que participó en la Guerra del Chaco. Para conseguir el efecto de verosimilitud, el autor afirmó que el diario del soldado anónimo había llegado a sus manos a través de un viajero alemán que lo obtuvo, a su vez, de un amigo suyo (alemán también), pero como estaba escrito en español ninguno de los dos sabía cuál era el aporte del documento; sin embargo, una vez en manos de Marín Cañas, este decide publicarlo.

El conflicto bélico narrado en el texto realmente tuvo lugar desde setiembre de 1932 hasta junio de 1935 entre Paraguay y Bolivia, la razón, como ya se dijo fue la disputa de la región conocida como el Chaco Boreal.

En cuanto a la publicación y a la recepción del texto en nuestro país, en El infierno verde: estrategias publicitarias de un folletín (2003), Alexander Sánchez Mora se refiere, precisamente, a las maniobras empleadas por Marín Cañas para su publicación por entregas. También, Álvaro Quesada Soto, en Uno y los Otros expone algunos aspectos de esta publicación por entregas y afirma que los lectores de esta no contaban, en principio, con elementos que les 
permitieran leer el texto como literatura, pues todos los indicios los llevaban a asumirlo como un reportaje periodístico o un testimonio histórico (Quesada 2002).

En relación con lo anteriormente expuesto, otro aspecto por considerar en esta novela tiene que ver, precisamente, con los recursos de verosimilitud utilizados, ante todo con la supuesta entrega del manuscrito a Marín Cañas por parte de un viajero alemán, hecho que da pie para la publicación por entregas, lo que según Manuel Picado Gómez legitima el relato y, además, está acorde "con la concepción instrumental del lenguaje que parecen manejar [...] los escritores del período" (Picado 1983: 63);, aludiendo a la generación del 40 y a la función referencial del texto literario, característica esencial, según este crítico, de la producción de esta etapa de la literatura nacional.

Precisamente, sobre la filiación de esta novela con los textos producidos por los escritores de la mencionada generación del 40, algunos críticos consideran que El Infierno Verde no se ajusta a las prácticas de escritura de este período, pues el mundo mostrado nada tiene que ver con la realidad costarricense. Por ejemplo, Jorge Valdeperas (1979) si bien afirma que tanto José Marín Cañas como Yolanda Oreamuno son escritores de la generación del 40, implica que lo son por un criterio meramente temporal, pues ninguno de ellos participa, a juicio de este crítico, de los presupuestos ideológico-artísticos de los demás escritores de esta generación, razón por la cual propone que los textos de ambos autores 'merecen' estudios específicos.

Álvaro Quesada Soto, en Breve Historia de la Literatura Costarricense (2010), no lo incluye dentro de la "generación del 40", sino en la conformada por escritores que nacieron alrededor del año 1900. Considera, además, que tanto las temáticas que desarrolla como su ejercicio de escritura en cuanto a la innovación de las técnicas narrativas no se ajustan a las de la "generación del 40".

Por otra parte, la crítica en general la considera una novela en la que se evidencia el absurdo de la guerra, esto porque los mismos personajes se preguntan cuál es la razón de esta y no logran encontrar una sola que sea válida. El mismo protagonista trata de dar una respuesta a su compañero Curriche cuando este le pregunta por qué razón van a la guerra.

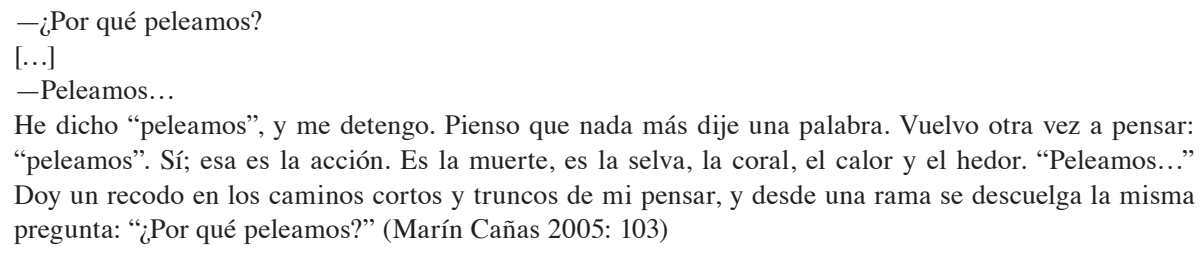

De esta manera, lejos de responder a la pregunta del joven soldado, lo único que puede el protagonista es hacerse a sí mismo la pregunta: “Por qué peleamos?”.

Para Quesada Soto, se trata de una novela antibélica que "denuncia la guerra como un ámbito de enajenación, destrucción y muerte, cuya presencia lleva a los protagonistas a una revisión crítica de los valores transmitidos por sus padres y maestros sobre la patria, la civilización y el heroísmo" (Quesada 2002: 230-231).

Para Ovares y Rojas, por su parte, los acontecimientos vividos por este soldado anónimo funcionan como pruebas que debe pasar el personaje en un proceso que lo llevará a la madurez. De acuerdo con estas autoras, la "prueba más importante es la guerra, que le sirve al soldado para adquirir autoconciencia” (Ovares y Rojas 1995: 121).

Otra de las afirmaciones de la crítica es proponer el espacio de la selva como un personaje más de la historia, caracterizado además por su crueldad, como lo señalan Virginia 
Sandoval de Fonseca (1978), al afirmar que la selva es inclemente, y Abelardo Bonilla, quien se refiere al Chaco como "un pedazo de dolor en el que operan por igual la muerte, la inclemencia, el calor y el polvo sofocantes" (Bonilla 1984: 318).

Óscar Alvarado Vega, en El Infierno Verde. Texto y Locura, propone que en esta novela prevalece el discurso de la locura. Se trata, según este autor, de "la locura [que] se origina a partir de la guerra y por la separación del discurso social, sin producir ambigüedades. En otras palabras, el texto plantea que no hay otra razón para la guerra, sino solo sinrazones" (Alvarado 2009: 128).

Finalmente, por su parte, Quesada Soto afirma que en la novela lo que prevalece es el discurso de la enajenación, pues en la historia que nos narra el protagonista, los "hombres adquieren las características de autómatas o máquinas bélicas, que actúan condicionados por impulsos exteriores, despojados de conciencia o voluntad propia" (Quesada 2002: 236). Así, esta enajenación transmite la sensación de que se vive en un mundo desarticulado, que se caracteriza por "la disgregación y el caos [...] la pérdida de identidad o ausencia de sentido, [...] un orden deshumanizante, ajeno y destructor" (Quesada 2002: 236).

\section{El cuerpo dócil}

Una vez hecha esta breve revisión de la crítica, corresponde a continuación establecer cómo se representa en esta novela el cuerpo humano en función del contexto bélico en el que se desarrolla la historia de la novela.

La representación del cuerpo dócil en este texto se puede evidenciar en cuatro momentos clave de la historia. Un primer momento corresponde al llamado que se hace al pueblo para que empuñe las armas y se defienda la soberanía del país. La pauta de este es el entusiasmo exacerbado, tanto por parte del protagonista como de parte de todos aquellos que responden a la convocatoria.

Como ya se ha dicho, el conflicto bélico entre Paraguay y Bolivia es el detonante de la historia. El protagonista de la novela, un joven abogado paraguayo de treinta años de edad decide enrolarse en el ejército, pues aparte de que considera que su vida en la ciudad es bastante mediocre y sin sentido, se ve motivado por el ambiente que se ha desplegado en la capital, tal y como se puede corroborar con la siguiente cita: "La cólera callejera me absorbió en su vorágine. Desde el 18 de junio Asunción ardía. Supe la primera noticia al bajar del tranvía de Tacambú. El motorista se lo había gritado a una vieja: "El fortín López ha caído en poder de Bolivia. ¿No lo sabía?” (Marín Cañas 2005: 10).

A partir de este incidente, en la ciudad el ambiente es cada vez más agitado. Según este joven abogado, en las escuelas también se alimentaba el patriotismo con el canto del himno nacional y los universitarios habían pedido al gobierno que les proporcionara armas para combatir. El protagonista, se ve así envuelto por un entusiasmo sin medida, razón por la que decide acudir al llamado y se enlista en el ejército: "Tranqué la oficina sin clientes [...] y recorrí las calles prendido en la llama popular" (Marín Cañas 2005: 11).

Como vemos, aunado al ambiente que se vive en Asunción, el mismo protagonista refiere que su desempeño como abogado lo tiene sumido en el ocio, pues no tiene clientes, de manera que al inscribirse en el ejército, cuenta con la esperanza de ser más productivo.

Para ser aceptado como soldado miente incluso en cuanto a su edad, pues la edad máxima permitida para enrolarse son veintinueve años, por esto a pesar de que él ya tiene treinta, asegura que apenas tiene los veintinueve años requeridos.

Como se puede apreciar, el protagonista responde en estas circunstancias al discurso nacionalista, cuyo objetivo era atraer voluntarios dispuestos a combatir al enemigo. En este 
sentido, el personaje empieza a dar señales de una obediencia absoluta: abandona el ejercicio de su profesión, miente en cuanto a su edad sin considerar la posibilidad de que al ser un poco mayor se vea afectada su participación en la batalla y, finalmente, abandona a la Mencha, su pareja, quien por supuesto no desea que él vaya a la guerra.

Este proceder, un tanto precipitado evidencia como el soldado responde a una programación social que lo requiere como fuerza de trabajo, en este caso concreto, en la defensa de su país.

Ahora bien, el entusiasmo no se limita sólo a este soldado, son muchos los que responden a la convocatoria, aunque no estén en las mejores condiciones para enrolarse.

La movilización ha sido un chuzazo en el músculo del pueblo. Los trenes vienen con hombres. Los verbales se despueblan. Son hombres macilentos, que huelen todavía a tragedia. Del Chaco irrumpen en las calles asunceñas hombres de la pampa, vaqueros cetrinos, jinetes corvetas, cadáveres de Humaitá, que se han puesto verticales. (Marín Cañas 2005: 14)

Como se colige de la cita anterior, quienes acuden a esta convocatoria vienen de diversos lugares del país y se dedican a labores también diversas, incluso se evidencia que algunos no están en buenas condiciones físicas, pues hay entre ellos jinetes corvetas y otros se describen como seres macilentos o como cadáveres que se han erguido para integrarse a la lucha.

En esta historia hay otros que tampoco cumplen con los requisitos para formar parte del cuerpo de soldados, pues no alcanzan la edad mínima de los veintidós años para ser aceptados y sin embargo logran reclutarse, tal es el caso de Ezcarru, según lo confirma el mismo protagonista cuando se refiere a este como "un muchachito de escasos veinte años, animoso y gallardo, que ha venido enrolado en la columna, porque quiere ser héroe" (Marín Cañas 2005: 19).

Como vemos, la tónica del proceso de reclutamiento es el entusiasmo extremo, son muchos lo que acuden al llamado. Luego viene la partida de las tropas, evento no menos entusiasta que el anterior. El protagonista lo describe de la siguiente manera:

\footnotetext{
¡La guerra! No hay rincón de la ciudad donde no esté ya 11a guerra. ¡La guerra! [...] Los batallones salen uno tras otro. En lanchas, en vapores, en trenes, en camiones. La ciudad tiene mil arrugas, y las mil arrugas vomitan mil hombres.

¡A Boquerón!

Trenes, vapores, camiones, hombres enracimados, pitos angustiosos de convoyes que parten. ¡A Boquerón!

Las hembras acompañan a los regimientos en la marcha al puerto. (Marín Cañas 2005: 15)
}

Como se puede constatar con la cita anterior, los hombres van 'enracimados', ya en este momento empiezan a perder no sólo su individualidad, sino también su condición de seres humanos, pues son 'vomitados' por la ciudad y se incluyen; además, en la enumeración de los medios en que son transportados: "Trenes, vapores, camiones, hombres enracimados, pitos angustiosos..."; es decir, en este punto se inicia un proceso de reificación.

Lo interesante de todo este proceso de la convocatoria es que se evidencia que la cotidianidad del protagonista se ve afectada y determinada por un ambiente en el que todos los discursos, el escolar, el político y el popular remiten al conflicto armado entre Paraguay y Bolivia, y a la urgencia de que el pueblo acuda al llamado de la guerra.

\footnotetext{
Vengo del ardor de las calles en estos primeros días en que todo parece vivir a espasmos. Soy una partícula de esa multitud enfurecida que ha gritado. Soy una ráfaga cualquiera, un pedazo de viento, una articulación de la total cólera que estremece a todos. Vengo del crisol ciudadano, como despojo hacia la muerte del empujón que hace el país para evitar la desmembración de una tierra lejana e intangible. (Marín Cañas 2005: 7)
} 
Una vez en la selva, el ambiente de alborozo de la partida se transforma en uno de angustia y desesperación para el soldado anónimo, debido sobre todo a las inclemencias del medio, pues el Chaco se caracteriza por ser un espacio inhóspito, el cual se describe como un pedazo de tierra calcinada y reseca. Además, para llegar a él primero debe atravesarse la selva y lo peor de este lugar es que no hay agua. En estas condiciones, la marcha de los soldados se torna en una pesadilla; no obstante, acatan sin chistar las constantes órdenes del teniente Zavala.

\footnotetext{
Zavala recorre la columna y da órdenes. Adelante van los zapadores abriendo brecha por entre la manigua, que se hace espesísima. Sin un ruido, los hombres se mueven en la sombra como bejucos [...] Vamos hacia el corazón de la selva [...] La caminata se hace lenta. (Marín Cañas 2005: 19)
}

De esta forma, se introduce el segundo momento clave de la representación del cuerpo dócil en esta historia. Este segundo momento lo determinan dos aspectos; el primero de ellos, la disciplina militar a la que son sometidos los soldados, tal como se muestra en la cita anterior; el segundo, el choque del soldado con la adversidad de la naturaleza, las exigencias de la marcha, el cansancio extremo y la espera. La siguiente cita es un ejemplo de lo pesado que les resulta a los soldados su movilización por la selva:

\begin{abstract}
Hemos reventado los tendones de las piernas. Zavala no nos da punto de reposo. Cada vez que alcanzamos un blocao, a quitarse las guerreras, a meter los brazos, las caras, el torso en los abrevaderos de las bestias, a dormir como pedazos de madera, y luego otra vez a caminar, a caminar, desierto adentro, rompiendo la jungla, abriendo brecha en la muralla de lianas, metiéndose en los polvazales inmóviles. (Marín Cañas 2005: 40)
\end{abstract}

Para este momento, se califica el esfuerzo corporal del soldado en relación con el de las 'bestias', y empieza también a recrudecer el problema del agua. Además, se nota que el proceso de reificación va en aumento al compararse el cuerpo con la madera.

En medio de estas marchas, Ezcarru, el jovencito que desea ser héroe, contrae paludismo; sin embargo, sus ansias de gloria lo llevan a ejecutar esfuerzos extremos, como se puede ver en el siguiente fragmento, en el que el protagonista está cuidándolo.

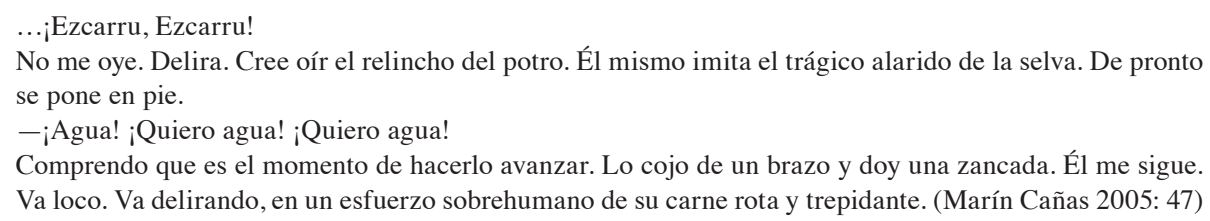

Pasajes como este se repiten durante el viaje por el Chaco. El agua cada vez escasea más, los cuerpos se deterioran y la espera por entrar en combate los impacienta hasta el hastío, como se evidencia en la siguiente cita:

\footnotetext{
Esperar. No hay otro camino. Esperar.

Esperar es cocinarse en el calor. Es permanecer detenido. Es convertirse en un tronco de la selva. En

Aquino llevamos una semana ya. Mañana entramos en la segunda. (Marín Cañas 2005: 27)
}

En efecto, aparte de la inclemencia del clima y de la falta de agua, la espera es un aspecto determinante en el proceso mediante los soldados se transforman en autómatas, como lo afirma el protagonista: "La angustia comienza a marcar su sello en las caras de todos. He visto que los soldados caminan como autómatas (Marín Cañas 2005: 31)". El propio soldado anónimo se va transformando en un autómata como bien lo asegura él mismo, cuando recuerda a Ezcarru quien muere después de ser mordido por una coral: "Pienso en Ezcarru. Es un solo instante. El hedor y el silencio me vuelven a despegar de mis recuerdos. No siento 
ya la vida. Camino como un autómata. Salto por instinto y avanzo sin saber hacia dónde, por dónde, desde dónde" (Marín Cañas 2005: 59).

A esta altura de la historia, el soldado anónimo reconoce que no es dueño ni de su ser ni de su voluntad, se limita únicamente a recibir órdenes del teniente Zavala sin cuestionarlas. Empieza, por otra parte, aceptar que el discurso glorioso de la guerra, que tanto escuchó en Asunción, no tiene ninguna relación con la realidad que vive en el Chaco; sin embargo, no se rebela, continúa en su puesto en actitud de espera.

Esta espera finaliza cuando el soldado anónimo participa en la primera batalla. Este hecho inicia el tercer momento clave de la historia.

Mientras se hallan atrincherados, se inicia el combate. Una granada hace explosión a dos pasos de donde se hallan el protagonista, su fiel compañero Nitzuga y el teniente Zavala; además, son atacados por el ejército boliviano con ráfagas de ametralladora. Precisamente debido a una de estas ráfagas Zavala pierde los ojos, pero en el calor del momento no se percata de lo que le ha sucedido. El soldado anónimo nos relata el hecho de la siguiente manera, Zavala ya ha perdido los ojos y pregunta

Como se puede apreciar, Zavala herido de muerte, antes que asumir su trágica condición, no acata más que a cumplir con su misión como soldado, reacciona como un guerrero autómata y con sable en mano continúa en la lucha.

Escenas como esta se repiten constantemente en la historia. Según lo narra el protagonista, los cuerpos mutilados abundan en el campo de batalla: "En las ramas y en los troncos la selva está exornada con macabros guindajos que la sombra uniformiza. Son cuerpos, más cuerpos (Marín Cañas 2005: 58)". Además, relata que se transportan muchos muertos y heridos en las angarillas. En una ocasión se refiere a un cuerpo mutilado que ve en una angarilla, este ha sido partido en dos y el comentario del soldado es que posiblemente la piernas que llevan no correspondan con el tórax, tal es la cantidad de cuerpos descuartizados que hay. Los cadáveres se enumeran entre los objetos que se encuentra en el campo de batalla, como se describe en el siguiente fragmento: "La luz va sacando de las sombras los contornos del frente. Alambres, troncos derribados, cadáveres, rescoldos" (Marín Cañas 2005: 73).

En medio de la violencia de los combates, el protagonista empieza a dudar si está vivo o muerto; no obstante, en un momento afirma lo siguiente: "Estoy vivo. Sé que estoy vivo porque me duelen los músculos de las piernas" (Marín Cañas 2005: 69). Sin embargo, esta desesperación e impotencia del soldado anónimo, se modifican en el instante en que se le asigna el manejo de una ametralladora: "Me han entregado la máquina, y yo me quedo pegado a ella, mirándola, mirándola, como si hubiera apoyado la cabeza entre los muslos de la ametralladora" (Marín Cañas 2005: 73).

La adquisición de esta ametralladora por parte del protagonista es un elemento muy importante en la representación del cuerpo dócil en esta novela, pues esta arma además de asegurarle al soldado cierta protección, también se va fusionar con su cuerpo a tal grado que el mismo personaje afirma lo siguiente: "Me abrazo a la ametralladora. La sinfonía de la máquina 
se riega...y los cuerpos que avanzan se tronchan... Una feroz alegría, la alegría de sentirme vivo, me hace apretar hasta el delirio el disparador de la máquina" (Marín Cañas 2005: 80).

Como se puede deducir, finalmente en la fusión del cuerpo del soldado con la ametralladora se manifiesta el hombre-máquina, sus movimientos, su posición corporal y, más aún, sus sentimientos responden al manejo óptimo del arma. De esta manera, si ya antes se había definido a sí mismo como un autómata, a esta altura de los hechos se ha convertido en el hombremáquina diseñado para matar y esto le causa tal placer que, incluso, establece una comparación entre el arma y el cuerpo femenino: "Me acomodo detrás de la ametralladora, la muevo sobre su eje, miro a ras del cañón. Es una hermosa máquina. Tiene unas piernas gruesas, abiertas. Así se abría la india, despatarrancada, cuando el sexo la enfurecía” (Marín Cañas 2005: 101).

Esta fusión hombre/máquina culmina la construcción del cuerpo dócil que el ejército requiere del soldado anónimo, tanto así, que de este punto en adelante el protagonista vive la transformación última, pues asume o comprende que su única función en el contexto en el que se encuentra es matar para sobrevivir.

De esta manera, el protagonista de la novela se transforma en el producto de lo que Álvaro Quesada denomina un impulso exterior, un orden que deshumaniza; sin embargo, desde la perspectiva de Michel Foucault, este personaje vendría a ser el producto final de la anatomía política, cuyas técnicas disciplinarias lo han convertido en un cuerpo dócil; es decir, en un cuerpo útil, cuya finalidad es matar.

El cuarto y último momento clave de la historia se inicia cuando después ser herido en una de sus piernas, el protagonista es enviado a un hospital que ha sido acondicionado para los heridos de guerra. Durante el viaje hacia el hospital, el soldado inicia un proceso de resignación, en este sentido, afirma lo siguiente: "Me trago el lloro, porque otros heridos van conmigo y se dejan llevar, enmudecidos, sin una rebeldía, sin una esperanza" (Marín Cañas 2005: 139).

Según lo afirma Foucault, la institución hospitalaria con sus normas y el aislamiento que supone, es uno de los espacios propicios en la conformación del cuerpo dócil, pues quien haya pasado por esta experiencia sabe que en este lugar no es dueño de su cuerpo. De hecho, en esta historia se ilustra el funcionamiento del hospital semejante al de una fábrica o, más bien, un matadero.

\footnotetext{
Las inyecciones se gastan copiosamente. Los médicos no cesan de poner inyecciones para acallar un poco la algarabía de dolor.

Cortan, serruchan, cosen, vendan. Todo se hace aprisa, como si el cuerpo fuera carne de caballo. El suelo de roca ha hecho más violento su tono de sangre. Algunas indias ayudan a los médicos. Trajinan trayendo agua, llevando vendas, sacando largas tiras de algodón. (Marín Cañas 2005: 89)
}

$\mathrm{Su}$ recuperación tarda meses, y en este lugar recibe la visita de su padre y de su abuelo, este le habla de la gloria de guerras pasadas en las que él participó y el protagonista no termina de entender cómo su abuelo puede hablar de batallas y matanzas con la pasión que lo hace. También en el hospital conoce a la Rusa, como llaman a la enfermera que lo atiende. Dice estar enamorado de esta mujer, pero tiene la certeza de que después de lo que ha vivido no puede estar ya con nadie, y cuando se recupera por completo de su herida, obedientemente, vuelve a la guerra. Admite que este regreso carece de la 'alegre algarabía' del primer viaje y plantea lo siguiente.

Dentro de mí, la batalla, el hospital, el boquete de Rocholl, la hediondez de los cuerpos, los discursos del abuelo me han trocado en un ser que está convencido de su fatalismo y lo acepta como algo irremediable [...] La guerra, como una querida, derrumba mis fuerzas, succiona mis energías, abate todas aquellas rebeldías y todos aquellos sueños. (Marín Cañas 2005: 161) 
De esta forma, el soldado anónimo regresa a experimentar no ya lo nuevo, sino lo conocido como un condenado a muerte, y lo expresa así al asegurar lo siguiente: "No he muerto, pero me siento hueco" (Marín Cañas 2005: 160). No obstante, para esta segunda experiencia en el frente sí tiene claro el porqué de esta guerra, no pelean por la defensa de la soberanía nacional, tal como lo cree al inicio de la historia, sino por los intereses de la Standar Oil en la explotación del petróleo en la región del Chaco, pero este saber no le genera ya reacción alguna, su proceso de de conformación como cuerpo dócil y útil ha sido consumado: su voluntad responde a las exigencias de una anatomía política que requiere se su fuerza productiva como soldado obediente.

Finalmente, después de revivir las mismas experiencias de su primera incursión en el campo de batalla, y de enterarse de la muerte de su fiel amigo Nitzuga, decide desertar junto con Rodríguez, otro de sus compañeros de guerra, y muere durante su huída.

\section{Notas}

1. Por esto la propuesta de Marx y Engels de la necesidad de un sistema educativo instrumentalmente adecuado para que el proletariado se libere del esquema de dominio capitalista.

2. En Discurso del Método, René Descartes realiza toda una exposición referida, según este pensador, al funcionamiento del cuerpo humano.

\section{Bibliografía}

Alvarado Vega, Óscar. 2009. El Infierno Verde. Texto y Locura. San José: EUNED.

Bonilla Baldares, Abelardo. 1981. Historia de la Literatura Costarricense. San José: STVDIUM.

Foucault, Michel. 2005. Historia de la Sexualidad. Vol I. Argentina: Siglo XXI Editores. 2005. Vigilar y Castigar. México: Siglo XXI Editores.

Marín Cañas, José. 2005. El Infierno Verde. San José: EUNED.

Marx, Karl y Federico Engels. 1987. La Ideología Alemana. México: Editorial Grijalbo.

Rojas, Margarita y Flora Ovares. 1995. 100 Años de Literatura Costarricense. San José: Ediciones Farben.

Picado Gómez, Manuel. 1983. Literatura/Ideología/Crítica. Notas para un estudio de la literatura costarricense. San José: Editorial Costa Rica.

Quesada Soto, Alvaro. 2002. Uno y los Otros. San José: Editorial de la Universidad de Costa Rica.

Sánchez Mora, Alexánder. 2003. "El infierno verde: las estrategias publicitarias de un folletín”. Revista Káñina. 27 (1): 11 -15

Sandoval de Fonseca, Virginia. 1978. Resumen de Literatura Costarricense. San José: Editorial Costa Rica.

Valdeperas, Jorge. 1979. Para una Nueva Interpretación de la Literatura Costarricense. San José: Editorial Costa Rica. 
